Article

\title{
Specific Yielding of Selective Laser-Melted Ti6A14V Open-Porous Scaffolds as a Function of Unit Cell Design and Dimensions
}

\author{
Volker Weißmann ${ }^{1,2}, *$, Jan Wieding ${ }^{1}$, Harald Hansmann ${ }^{2}$, Nico Laufer ${ }^{3}$, Andreas Wolf ${ }^{1}$ and \\ Rainer Bader ${ }^{1}$ \\ 1 Biomechanics and Implant Technology Research Laboratory, Department of Orthopedics, \\ University Medicine Rostock, Doberaner Strasse 142, Rostock 18057, Germany; \\ jan.wieding@med.uni-rostock.de (J.W.); andreas.wolf@med.uni-rostock.de (A.W.); \\ rainer.bader@med.uni-rostock.de (R.B.) \\ 2 Faculty of Engineering, University of Applied Science, Technology, Business and Design, \\ Philipp-Müller-Str. 14, Wismar 23966, Germany; h.hansmann@ipt-wismar.de \\ 3 Institute for Polymer Technologies e.V., Alter Holzhafen 19, Wismar 23966, Germany; laufer@ipt-wismar.de \\ * Correspondence: weissmann@ipt-wismar.de; Tel.: +49-03841-758-2388; Fax: +49-03841-758-2399
}

Academic Editors: Harrie Weinans and Amir A. Zadpoor

Received: 17 April 2016; Accepted: 14 July 2016; Published: 18 July 2016

\begin{abstract}
Bone loss in the near-vicinity of implants can be a consequence of stress shielding due to stiffness mismatch. This can be avoided by reducing implant stiffness, i.e., by implementing an open-porous structure. Three open-porous designs were therefore investigated (cubic, pyramidal and a twisted design). Scaffolds were fabricated by a selective laser-melting (SLM) process and material properties were determined by conducting uniaxial compression testing. The calculated elastic modulus values for the scaffolds varied between 3.4 and $26.3 \mathrm{GP}$ and the scaffold porosities between $43 \%$ and $80 \%$. A proportional linear correlation was found between the elastic modulus and the geometrical parameters, between the elastic modulus and the compressive strengths, as well as between the strut width-to-diameter ratio $(a / d)$ and elastic modulus. Furthermore, we found a power-law relationship between porosity and the modulus of elasticity that characterizes specific yielding. With respect to scaffold porosity, the description of specific yielding behaviour offers a simple way to characterize the mechanical properties of open-porous structures and helps generate scaffolds with properties specific to their intended application. A direct comparison with human bone parameters is also possible. We generated scaffolds with mechanical properties sufficiently close to that of human cortical bone.
\end{abstract}

Keywords: Ti6Al4V; open-porous scaffolds; selective laser melting; mechanical properties

\section{Introduction}

Ti6Al4V alloy is widely used to fabricate many components of orthopaedic implants, such as the femoral stem or the acetabulum component of a total hip joint replacement [1,2]. Titanium alloy offers many favourable properties, such as good biocompatibility, no allergenicity and a moderate elastic modulus ( 110 GPa) [3], which, however, is still much higher than that of the adjacent bone stock (typically, 10-20 GPa [4]). This phenomenon known as stiffness mismatch can result in stress shielding [5,6], which has been identified as a cause for the aseptic loosening of orthopaedic implants, the main cause of their failure $[7,8]$. In order to reduce the risk of stress shielding, metal alloy implant components can be fabricated for instance with open-porous structures that provide an elastic modulus low enough for this specification [9-14]. 
Open porous structures were generated and tested as irregular [15-18] and regular or non-stochastic scaffolds $[9,10,19-26]$. Since trabecular bone is irregular, irregular structures may be a more authentic imitation than regular ones. Imwinkelried et al. [15] described an open-porous titanium foam with a stiffness comparable to that of cortical and trabecular bone depending on the porosity that ranged from $50 \%$ to $80 \%$. Due to the non-spherical shape of the space holder particles, their scaffolds showed an anisotropic behaviour.

In contrast, Li et al. [16] investigated a sponge-like titanium scaffold with a macrostructure similar to that of cancellous bone with nearly no anisotropic behaviour. However, due to this irregularity, controlling the mechanical properties and geometrical parameters, e.g., pore size or defined structural modulus, is complicated. Pore sizes in the range of 100-600 $\mu \mathrm{m}$ were found in one specimen [18]. Therefore, as it seems, irregular structures are less suited for fabricating load bearing implants with defined mechanical properties.

Additive manufacturing (AM) methods, such as selective laser melting (SLM), are widely used for fabricating open-porous metals and alloys $[22,25,27]$. They afford the means for the development and manufacturing of structures with defined mechanical and geometrical properties, e.g., with an elastic modulus in the range of that of human bone [4,28-30]. Furthermore, the properties of the fabricated scaffolds can be directly controlled by the geometrical shape and the composition of different parameter sets [31,32]. However, the material used [22,33-37], the variation in geometry [38,39] as well as the additive manufacturing technique (EBM—electron beam melting or SLM—selective laser melting), all have an important impact on the properties of a scaffold.

Important for the evaluation of the mechanical properties of open-porous structures is, moreover, the accuracy of the fabricated scaffolds. Marin et al. [40] demonstrated that a cellular solid with a porosity of $63 \%$ and $72 \%$ can be used in biomedical applications to enhance osseointegration. Geetha et al. [33] discussed the biomechanical compatibility, thermomechanical processing and surface conditions of many metallic materials. In reference [41], the author cultured human osteoblasts under static and dynamic conditions with results that confirmed the suitability of open-porous structures for biomedical applications.

Particularly, the employed additive manufacturing technologies are critically characterized by the effects of the process. The microstructure and also mechanical properties are affected by the process parameters $[42,43]$ as well as by the thermal after-treatment $[44,45]$ of structures. In the evaluation of open-porous structures, strut orientation and loading angles [24,46-48] as well as the functional correlation between porosity and elastic modulus [19] play a critical role.

To avoid stress shielding of the adjacent bone tissue around stiff implants, the modification and reduction of the scaffold stiffness is necessary $[7,8]$. The mechanical properties of bone vary considerably and can be several times higher [49]. For successful application of an additively manufactured structure, its mechanical properties must be adjusted to match that of human bone. Such adjustment offers the opportunity to overcome the interfacial difference between the elastic properties of human bone and metallic implants. In this way, bone stress shielding problems caused by the extreme stiffness of the metal implant could be solved. For this purpose, it is necessary to adapt the mechanical properties according to patient-specific requirements. This includes e.g., a similar elastic modulus to human cortical bone (i.e., 15-20 GPa) [4,28].

The aim of the present study therefore was to determine experimentally the influence exerted by the design and the configuration of a scaffold's unit cell on its porosity and compressive modulus. Three design variations of additively manufactured scaffolds, each with at least three configurations, were investigated.

Studies are known that provide a characterization of porous structures, including geometric or material-specific factors [46,50,51]. Often in the foreground is the comparison of the moduli of porous models with full-body models, which only partially reflects the possibilities of a structure. In this study, characterization includes also the identification of the functional relationship between experimentally determined porosity and modulus of elasticity. This characterization method provides 
a possibility to directly compare different geometric cell variants and dimensions as well as to classify the attainable strengths. Specific yielding is of particular importance here, offering an excellent opportunity to establish a direct correlation between porosity and elastic modulus. A special benefit is derived through the classification of structures, which, in order to avoid failure, must offer adequate structural rigidity at a low weight and sufficiently high porosity. The evaluation of specific yielding as a magnitude of influence on the failure behaviour of a component equally takes into account the influence of porosity and material parameters (elastic modulus), i.e., design and material. This new approach is of great practical importance with regard to implant engineering. As the determining factor for the characterization of deformation resistance, specific yielding (depending on the elastic properties of materials and the geometrical conditions of the component) offers an invaluable benefit when assessing the suitability of a given geometry/structure for medical applications (implant). The consideration of specific yielding not only allows a comparison between different structures and porosities but also a direct comparison with human bone parameters. Specific yielding can facilitate the presentation of different bone parameters. Based on this relationship, structures can be directly classified in respect to their biomedical application.

\section{Materials and Methods}

\subsection{Unit Cell Designs and Configuration}

Using CAD software for this study (PTC Creo, Version 2.0, Parametric Technology Corporation, Needham, MA, USA), we developed three different open-porous structures with three different unit cell designs. Scaffolds were fabricated via an SLM process provided by an external manufacturer (SLM solutions GmbH, Lübeck, Germany). Three designs featuring different strut orientation and structural composition were investigated:

- a cubic design $(\mathrm{C})$,

- a truncated pyramidal design $(\mathrm{P})$, and

- a twisted design with crossing struts $(\mathrm{T})$.

The pyramidal design was a truncated pyramid with a square base and a parallel top surface, with the top surface being smaller than the base surface. The twisted design features crossing struts. Schematic drawings of the three investigated designs (cubic, pyramidal and twisted) are shown in Figure 1.
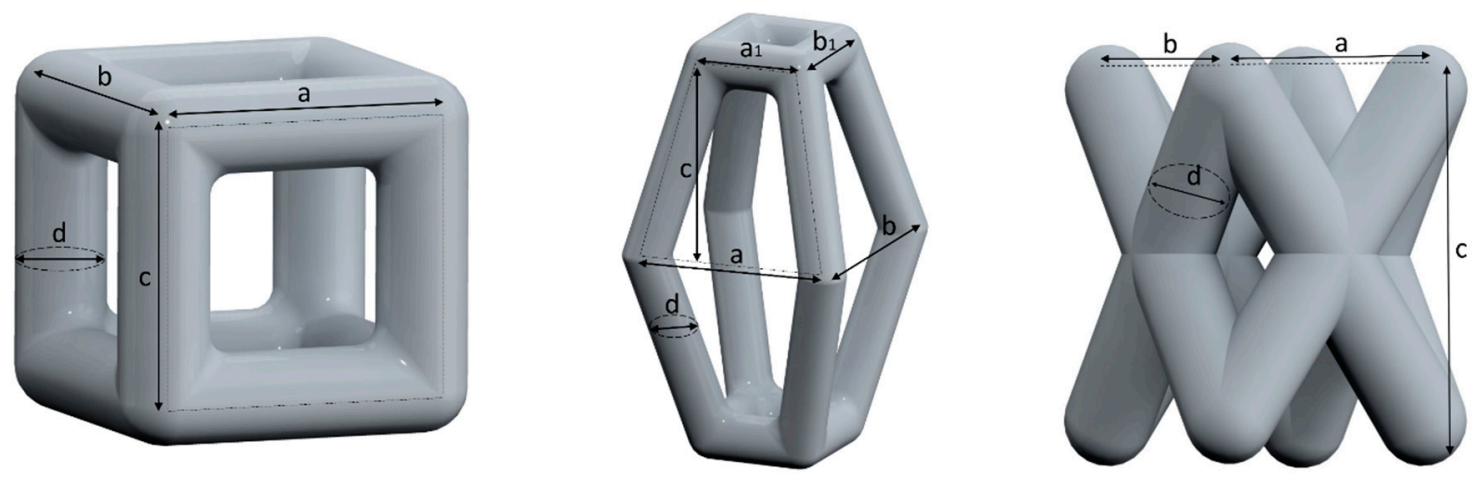

Figure 1. Structural composition of the three investigated designs: cubic (left), pyramidal (middle) and twisted (right). The geometrical parameters for the structures are height (c), width $(a)$ and depth (b) of each unit structure. Struts from all designs had a circular cross-section with the strut diameter $(d)$. The pyramidal design had additional parameters $a 1$ and $b 1$ for width and depth of the smaller base and top surface, respectively. 
Geometrical parameters for the three designs (cubic, pyramidal and twisted) were varied. For the cubic and pyramidal design, four different scaffold variations were generated, and three variations for the twisted design. This includes the dimensional variation of the basic cell (i.e., edge length and element height) as well as the strut diameter. The mechanical properties were therefore analysed with regard to the variations in the structural composition of the scaffolds. The geometric parameters for the investigated scaffolds are listed in Table 1.

Table 1. Overview of the geometric parameters for the unit cell variants of the three investigated designs (cubic, pyramidal and twisted, $n=5$ for each configuration) as well as the dimensions for the large-size scaffold for mechanical testing. All values are derived from CAD data and are given in $\mathrm{mm}$.

\begin{tabular}{|c|c|c|c|c|c|c|c|c|c|}
\hline \multirow[b]{2}{*}{$\begin{array}{c}\text { Basic } \\
\text { Design }\end{array}$} & \multirow[b]{2}{*}{ Configu-Ration } & \multicolumn{6}{|c|}{ Unit Structure } & \multicolumn{2}{|c|}{ Scaffold Structure } \\
\hline & & $\begin{array}{l}\text { Height } \\
\text { (c) }\end{array}$ & $\begin{array}{l}\text { Width } \\
\text { (a) }\end{array}$ & $\begin{array}{l}\text { Width } \\
\left(a_{1}\right)\end{array}$ & $\begin{array}{l}\text { Depth } \\
(\text { b) }\end{array}$ & $\begin{array}{c}\text { Depth } \\
\left(b_{1}\right)\end{array}$ & $\begin{array}{l}\text { Strut Diameter } \\
(d)\end{array}$ & $\begin{array}{l}\text { Height } \\
(H)\end{array}$ & $\begin{array}{l}\text { Diameter } \\
\text { (D) }\end{array}$ \\
\hline & $\mathrm{C} 1$ & 4.0 & 4.0 & - & 4.0 & - & 2.2 & 30.1 & 26.1 \\
\hline & $\mathrm{C} 2$ & 4.0 & 4.0 & - & 4.0 & - & 1.8 & 29.1 & 25.6 \\
\hline & $\mathrm{C} 3$ & 3.0 & 3.0 & - & 3.0 & - & 1.8 & 20.2 & 16.8 \\
\hline & C5 & 2.0 & 2.0 & - & 2.0 & - & 0.8 & 10.6 & 8.1 \\
\hline \multicolumn{10}{|c|}{ Truncated Pyramid } \\
\hline & P1 & 6.0 & 6.0 & 3.0 & 6.0 & 3.0 & 2.2 & 37.2 & 35.2 \\
\hline & $\mathbf{P 2}$ & 4.0 & 4.0 & 2.0 & 4.0 & 2.0 & 1.5 & 25.4 & 23.2 \\
\hline & P3 & 3.0 & 3.0 & 1.5 & 3.0 & 1.5 & 1.1 & 19.6 & 17.6 \\
\hline & $\mathrm{T} 2$ & 4.0 & 2.83 & - & 2.83 & - & 1.0 & 18.0 & 17.0 \\
\hline a & T3 & 3.0 & 2.12 & - & 2.12 & - & 0.9 & 18.0 & 17.0 \\
\hline
\end{tabular}

Based on these unit structures, large cylindrical scaffolds for mechanical testing were created as linear patterns of the single designs (Figure 2). Porosity as well as the mechanical properties of the scaffolds were varied by changing the scale dimension of the designs and the strut diameter. The height $(H)$ of the scaffolds was an even multiple of those of the unit structure so that its structure remained intact in height. Note that, for each scaffold, the $H / D$ ratio was between one and two in order to avoid buckling during compression testing as per the relevant testing standard (DIN EN 50106; Testing of Metallic Materials, Compression Test).

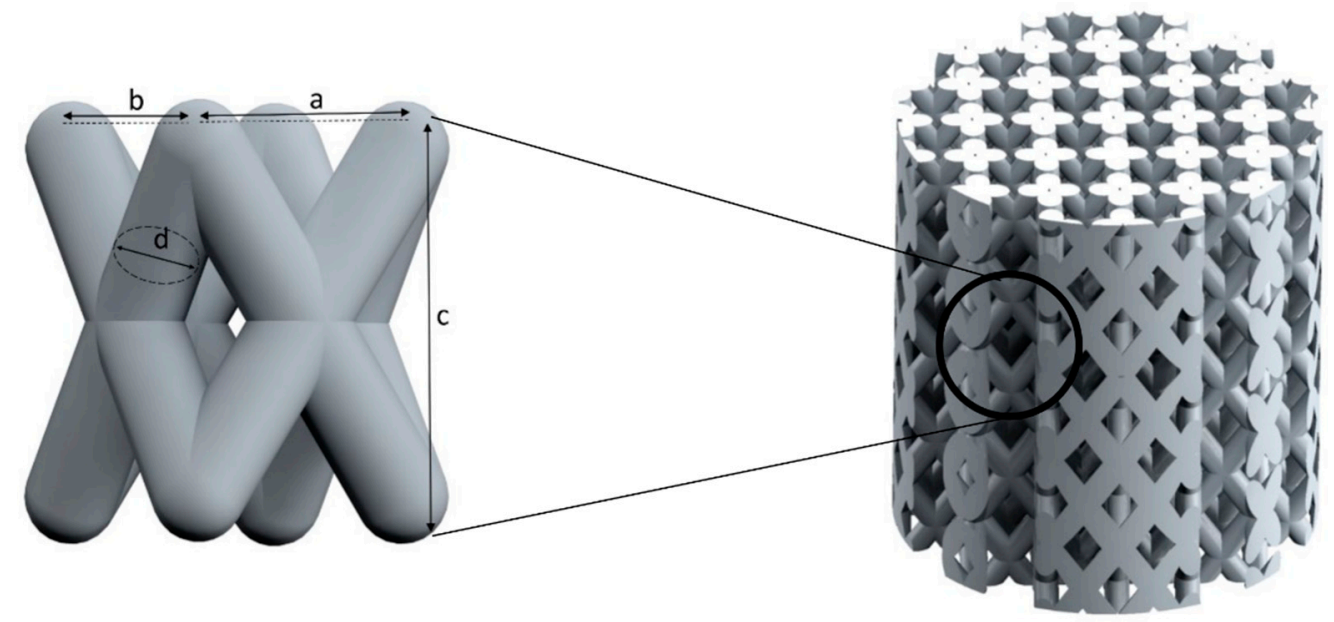

Figure 2. Unit cell (twisted design) and a large scaffold of diameter, $D$, and height, $H$, for mechanical testing-here as an example for the representation of the test body design. 


\subsection{Fabrication of the Scaffolds via an SLM Process}

Based on the datasets of the CAD models, all scaffolds were fabricated via selective laser melting using titanium powder (Ti6Al4V) in an ultra-pure argon atmosphere. The powder complies with the requirements of ASTM F 67 (ASTM-American Society for Testing and Materials) and has a determined mean particle size of $43.5 \mu \mathrm{m}$.

The scaffolds were fabricated by SLM solutions GmbH, Lübeck, Germany, with the SLM 280 using a continuous-wave Ytterbium fibre laser. All parts were built using an identical energy density $\left(\mathrm{J} / \mathrm{mm}^{3}\right)$. The energy density $(E)$ is defined by the following equation [52]:

$$
E=\frac{P}{v \times d \times t}
$$

where $P$ is laser power, $v$ is scan speed, $h$ is hatch spacing and $t$ is layer thickness.

All parts were built on top of a substrate plate with a support structure and in the same orientation. After fabrication, the samples were removed from the substrate plate. The support structures were removed using wire electro discharge machining. For the determination of density $\rho_{0}$, a fully dense part (10 mm diameter and $6 \mathrm{~mm}$ height) was manufactured.

\subsection{Calculating the Scaffold Porosity}

In order to verify the reproducibility and the accuracy of the fabrication process compared to the CAD data, the porosity for the scaffolds with different designs was measured. For scaffolds fabricated using the cubic, pyramidal and twisted designs, the porosity of their CAD models (Porosity_CAD) was determined using the following expression:

$$
\text { Porosity_CAD }=\left(1-\frac{V_{\text {str }}}{V_{\text {cyl }}}\right) \times 100 \%
$$

where $V_{\text {str }}$ is the volume of the CAD scaffold struts and $V_{\text {cyl }}$ is the overall volume enclosed by the outer periphery.

To verify the accuracy of the scaffold fabrication process, the porosities of the generated scaffolds (experimental porosity) were determined and then compared to the porosity of their CAD models:

$$
\text { Porosity_experimental }=\left(1-\frac{\rho_{\mathrm{sc}}}{\rho_{0}}\right) \times 100 \%
$$

where $\rho_{0}$ is the density of non-porous Ti6Al4V (i.e., $4.43 \mathrm{~g} / \mathrm{cm}^{3}$ ) and $\rho_{\mathrm{sc}}$ is the density of the manufactured scaffolds, calculated by weight and volume of the scaffolds. The weight is determined by means of scales (Mettler Toledo XS 105, exactness $0.1 \mathrm{mg}$, Gießen, Germany). The volume was determined by means of measurement in a digital microscope (VHX 2000, Keyence, Neu-Isenburg, Germany).

\subsection{Determination of the Mechanical Properties with Compression Testing}

All scaffolds were mechanically tested in a uniaxial compression test, according to DIN standard (DIN EN 50106). A universal testing machine (Z 250 Zwick GmbH \& Co., KG, Ulm, Germany) was used to conduct the mechanical testing.

Compression testing of the samples was performed with a constant traverse velocity of $2 \mathrm{~mm} / \mathrm{min}$. All tests were performed under standard atmospheric conditions ( $24{ }^{\circ} \mathrm{C}, 50 \%$ rel. humidity). The parts were tested in building direction and with five specimens. Values for load and displacement were continuously recorded during testing. All fabricated scaffolds were tested until mechanical failure occurred or the maximum capacity load of the testing machine was reached. 
The load vs. displacement curves were used for the determination of the material properties of the scaffolds, i.e., structural modulus, compressive strength and compressive strain.

Strain was measured by the actual displacement of the crossheads. Each static compression test resulted in a stress-strain curve. The following values deviated from the compression test: the elastic modulus was defined as the slope of the compressive stress-strain curve in the linear elastic region, the compressive strength was calculated by the support area and maximum load before the first fracture or decrease in load occurred, and the compressive strain was defined as the corresponding strain to the compressive strength.

Evaluation is always based on the entire cross section of the scaffold. The deviated elastic modulus thus corresponds to the structural modulus of the scaffold. The determined strain refers to the cross-sections of the entire test part and can be described as nominal. To facilitate understanding and for comparison of this study with similar ones on porous materials, we will name the structural modulus elastic modulus and nominal strain compressive strain. Nevertheless, the exact definitions given above need to be kept in mind when interpreting the data.

\section{Results}

None of the samples showed untypical failure behaviour, e.g., lateral buckling or slipping, and all tested samples were considered for results evaluation.

\subsection{Porosities of the Scaffolds}

Results of calculated porosities for all designs and configurations are shown in Figure 3. The representation of the roughness is shown in Figure 4.

For scaffolds with the cubic design, CAD porosity ranged from $43 \%$ to $73 \%$. The twisted design revealed a similar porosity of $55 \%$ to $67 \%$, while the pyramidal design with $74 \%$ to $80 \%$ showed the highest porosity. For the twisted design, experimental porosity revealed a minor deviation compared to the CAD porosity of $-2.2 \%, 3.0 \%$ and $-2.0 \%$ for $\mathrm{T} 1$, $\mathrm{T} 2$ and $\mathrm{T} 3$, respectively. The pyramidal design had a lower porosity than the CAD model in all cases. The smallest and largest divergence was found, respectively, for model P4 with $1 \%$ and for model P2 with $2.3 \%$. Scaffolds with cube design are smaller in designs 1 and 2 and bigger in designs 3, 4 and 5 than calculated in the CAD model. Design 1 with $6.1 \%$ shows the biggest difference between $\mathrm{CAD}$ and experimental porosity and design 5 the smallest difference with $0.1 \%$.

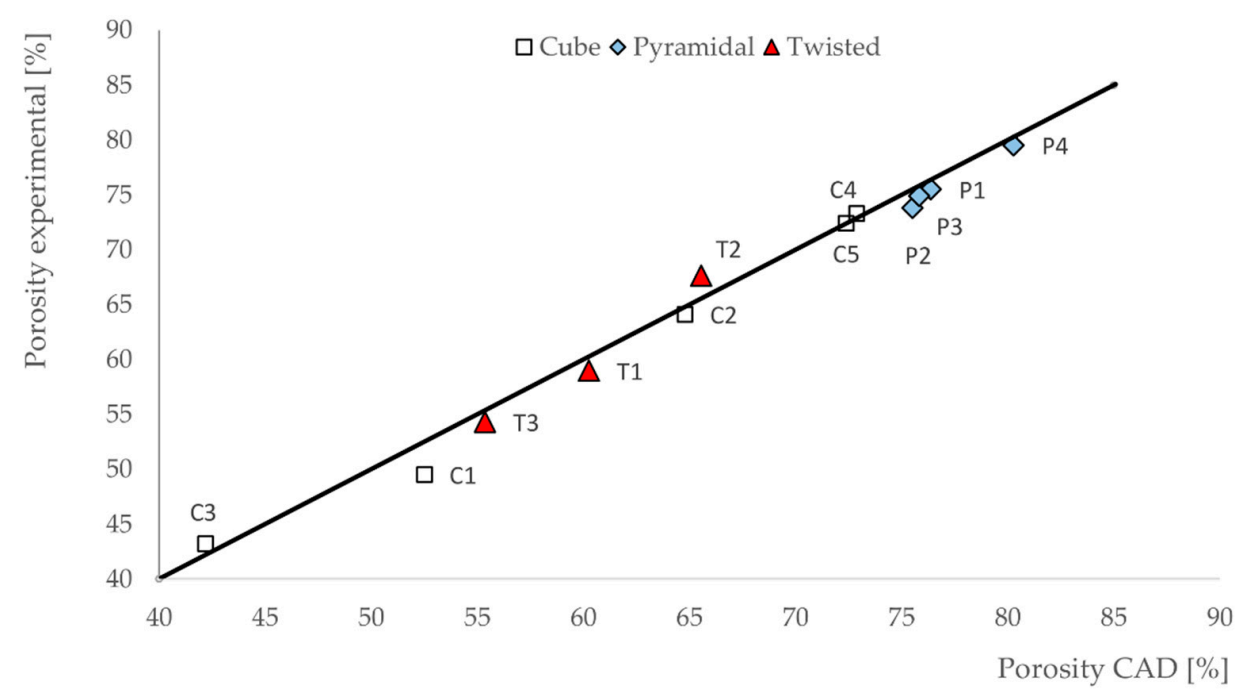

Figure 3. Porosity of the three investigated designs, i.e., cubic, pyramidal and twisted, and all of their configurations. The results for CAD porosity are shown in comparison to the experimentally determined porosity. 

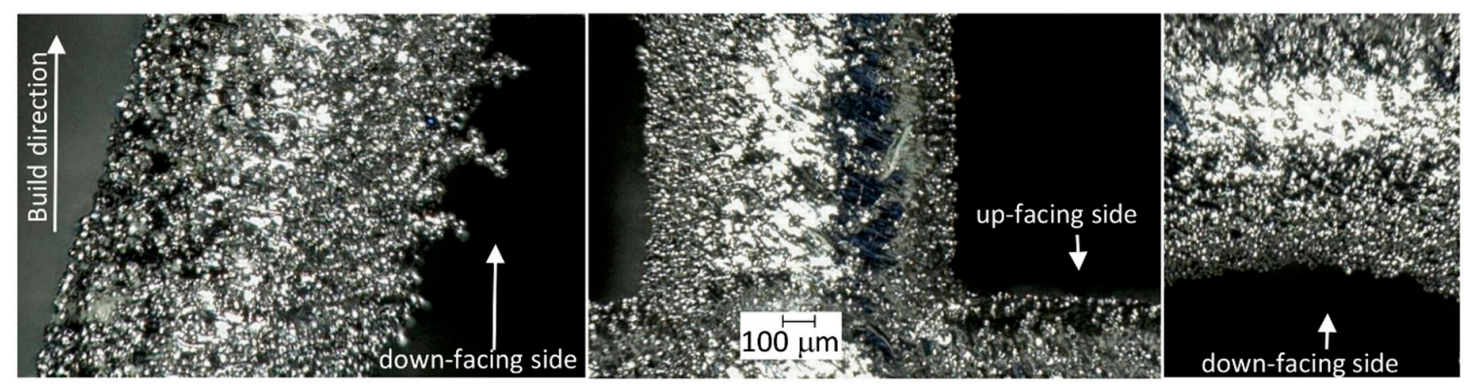

Figure 4. Representation of the roughness of struts as a result of their individual orientations; (Left)—slanted struts show at the bottom (the powder bed side) a build-up of molten powder particles; (Centre)-image vertical struts, as well as the top of horizontal struts (the powder bed opposite) show no build-up of powder particles; (Right) - horizontal struts show at the bottom (of the powder bed facing side) a build-up of melted powder particles.

\subsection{Compressive Modulus, Strength and Strain of the Scaffolds}

Results for all scaffolds after mechanical testing are listed in Table 2.

Table 2. Results from mechanical testing ( $n=5$ for each design).

\begin{tabular}{cccc}
\hline Design & $\begin{array}{c}\text { Elastic Modulus } \\
(\mathbf{G P a})\end{array}$ & $\begin{array}{c}\text { Compressive Strength } \\
\mathbf{( M P a )}\end{array}$ & Compressive Strain (\%) \\
\hline C1 & $18.9 \pm 1.2$ & $510.7 \pm 67.8$ & $4.2 \pm 2.6$ \\
C2 & $10.9 \pm 1.0$ & $369.7 \pm 40.3$ & $4.0 \pm 0.7$ \\
C3 & $21.6 \pm 1.9$ & $761.1 \pm 108.6$ & $4.6 \pm 1.3$ \\
C4 & $7.2 \pm 0.5$ & $203.1 \pm 50.4$ & $2.7 \pm 0.6$ \\
C5 & $9.3 \pm 0.3$ & $184.4 \pm 2.1$ & $3.2 \pm 0.3$ \\
\hline P1 & $5.7 \pm 0.3$ & $153.9 \pm 15.5$ & $3.0 \pm 0.3$ \\
P2 & $6.9 \pm 0.8$ & $164.1 \pm 44.8$ & $2.6 \pm 0.7$ \\
P3 & $5.2 \pm 0.6$ & $142.8 \pm 13.3$ & $2.8 \pm 0.1$ \\
P4 & $3.4 \pm 0.2$ & $121.1 \pm 10.9$ & $3.6 \pm 0.2$ \\
\hline T1 & $21.4 \pm 0.7$ & $316.9 \pm 2.3$ & $2.8 \pm 0.2$ \\
T2 & $16.7 \pm 0.6$ & $215.0 \pm 3.0$ & $3.2 \pm 0.2$ \\
T3 & $26.3 \pm 1.9$ & $402.9 \pm 7.9$ & $4.1 \pm 0.1$ \\
\hline
\end{tabular}

Figure 5 shows scaffolds representing each design after mechanical testing with the location and direction of the fractured struts.

The maximum strains derived from the load vs. displacement curves revealed values between $2.6 \%$ and $4.6 \%$.

Results of the calculated elastic modulus and compressive strength for each variant of the three investigated designs (cube, pyramid and twisted) are shown in Figure 6. The elastic modulus was calculated considering the slope of the elastic response from the stress-strain relationship and revealed values between 3.4 and $26.3 \mathrm{GPa}$. The maximum compressive strength e revealed values between 121 and $761 \mathrm{MPa}$. 


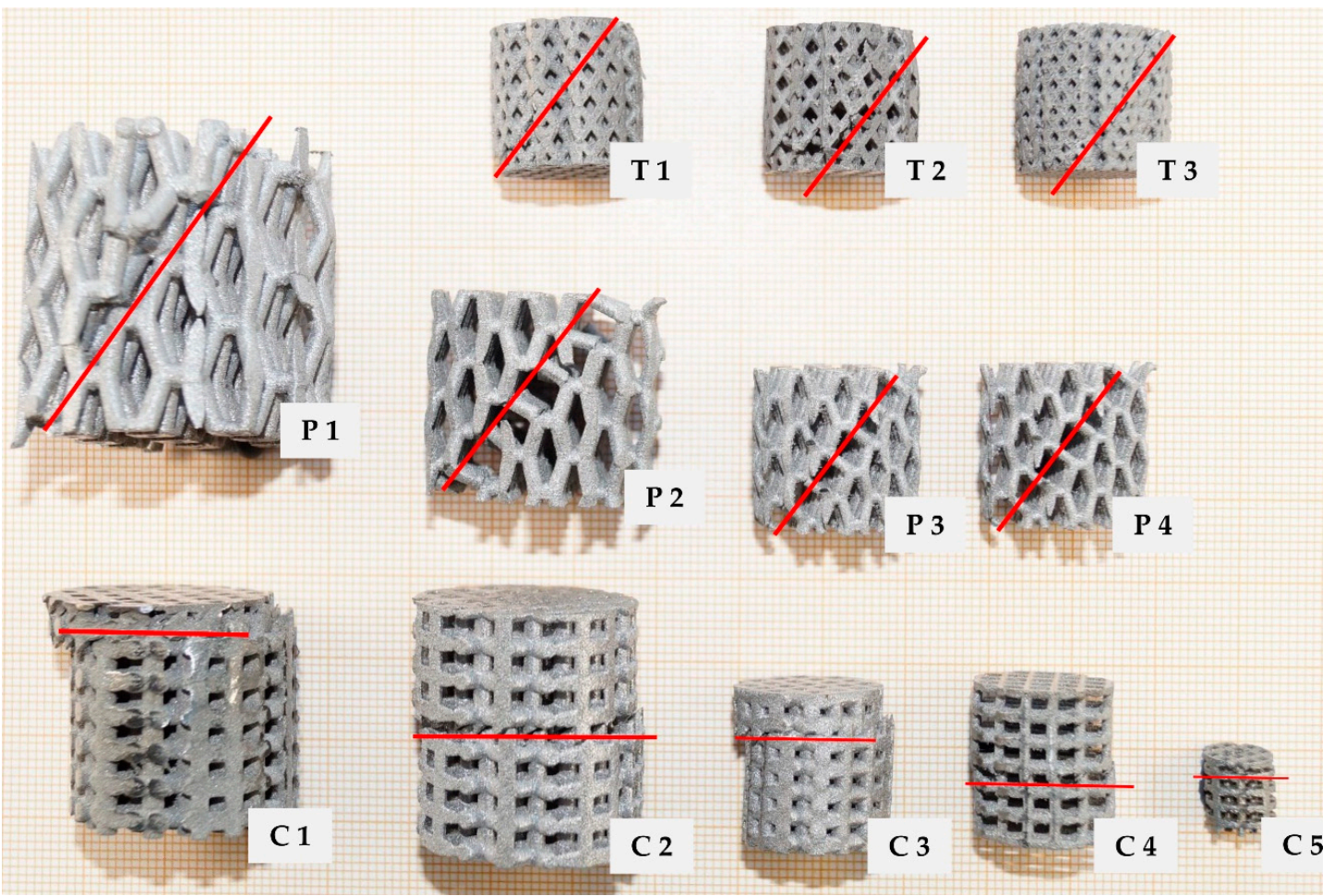

Figure 5. Macroscopic view-overview of tested samples. Failure courses are identified in these figures by a red line for the macroscopically visible line of fracture. Twisted and pyramidal designs showed shear deformation at an angle of ca. $45^{\circ}$. The cubic design showed a layer-by-layer failure mechanism.

a Compressive strength $\quad$ Elastic modulus

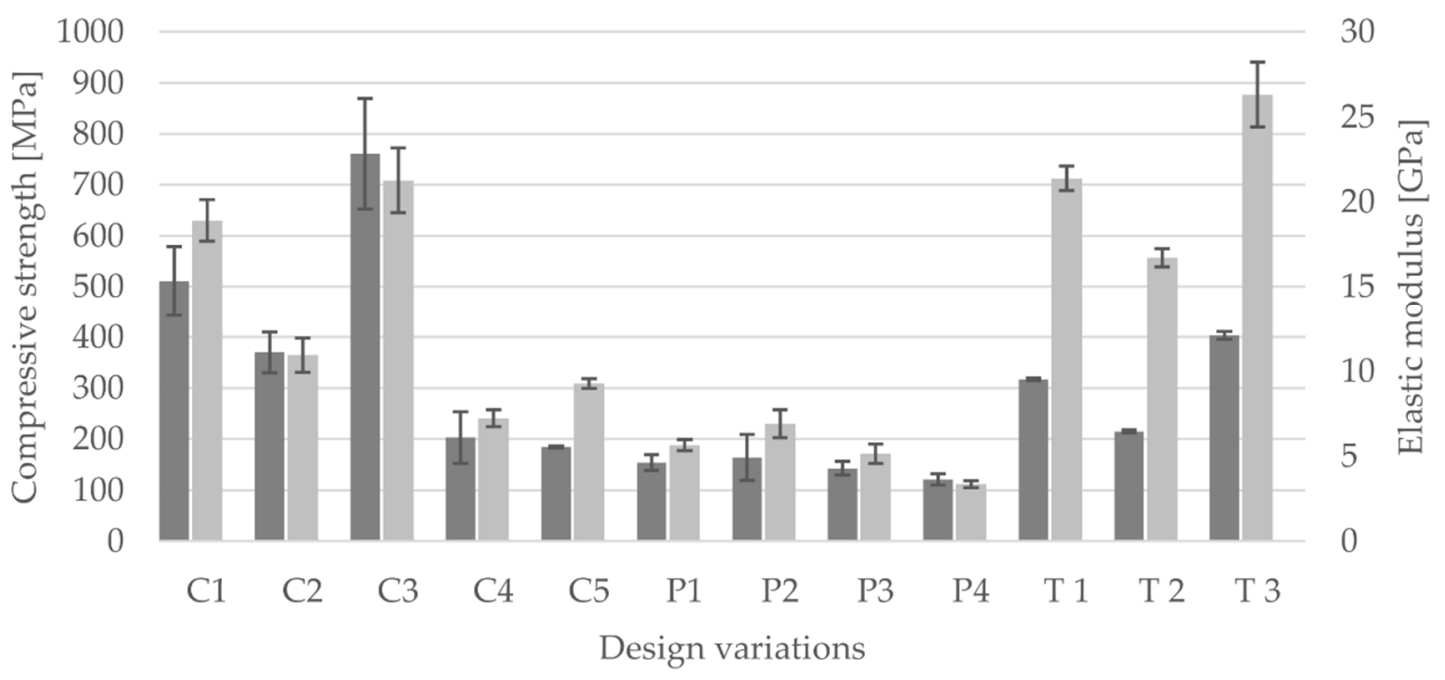

Figure 6. Elastic modulus and compressive strength for the three investigated designs (cube, pyramid and twisted) and the different configurations as calculated from axial compression testing. Results are shown as mean values with the corresponding standard deviation ( $n=5$ for each design).

The highest elastic modulus was found for the twisted design T3 and the highest compressive strength for the cubic design C3. The pyramidal design P4 revealed the lowest value for elastic modulus as well as for the compressive strength. 
The results of compressive strength varied between 121.1 and 761.1 MPa. The lowest compressive strength was found for the pyramid design and the highest for the cube design. Percentage differences between the highest and lowest compressive strength for the cube, the pyramid and the twisted design were $24.2 \%$ (C3 and C5), 73.8\% (P4 and P2) and 53.3\% (T2 and T3), respectively.

The biggest differences in the scaffolds were found for the cube design and the smallest differences for the pyramidal design.

\subsection{Correlations between Geometrical and Mechanical Properties}

Changing the geometrical parameters influenced mechanical behaviour. The correlations between porosity and elastic modulus in the three designs are shown in Figure 7. For all designs, linear correlation with a high coefficient of determination was found. It was $98.3 \%, 89.1 \%$ and $96.6 \%$ for the cubic, pyramidal and twisted design, respectively. Furthermore, for all designs, the elastic modulus decreased with increasing porosity. The increase of the linear regression indicates how massively a change in porosity can influence the elastic modulus. The increase of the linear regression for the twisted design, -0.698 , is steeper than for the cubic and pyramidal designs, i.e., -0.452 and -0.560 , respectively.

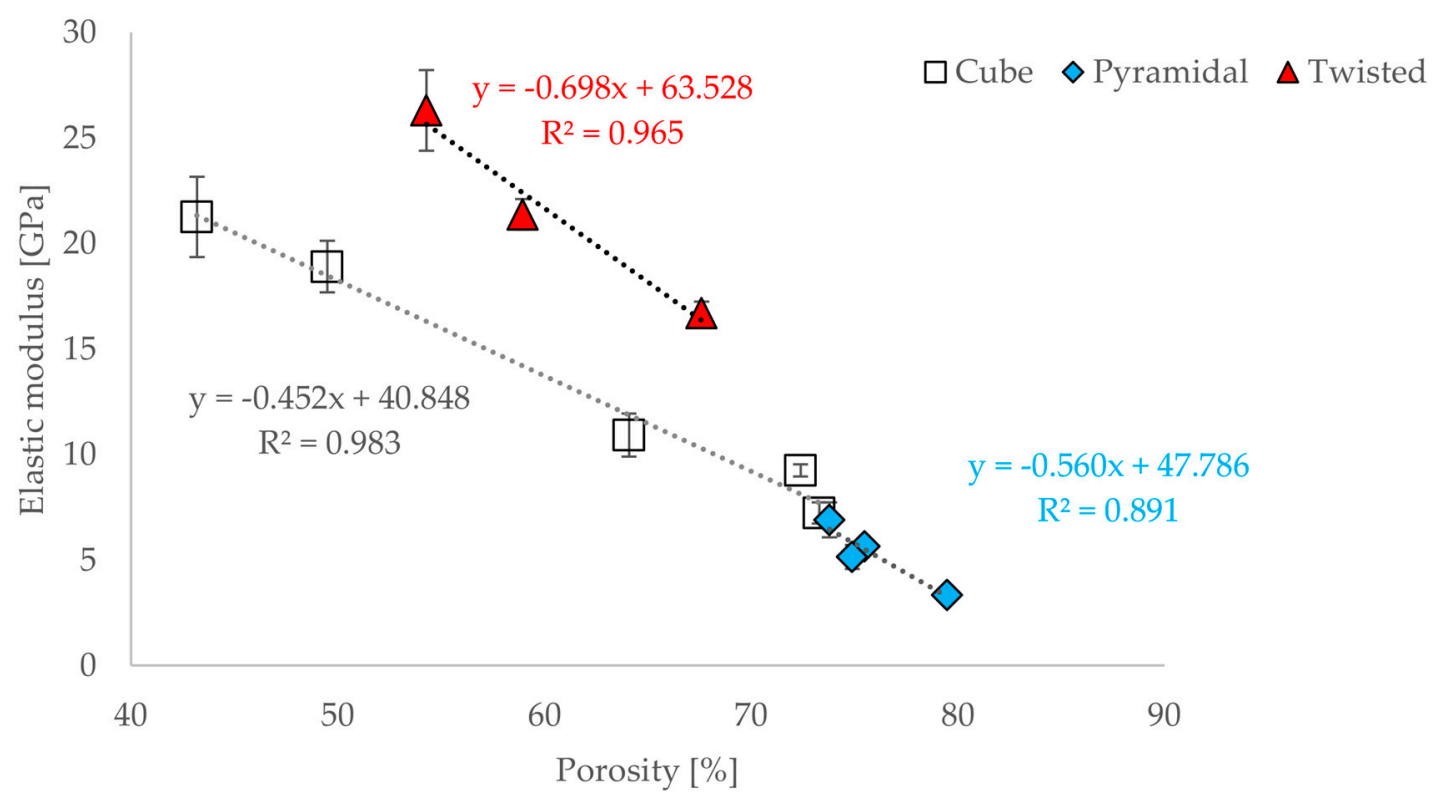

Figure 7. Correlation between porosity and elastic modulus in each of the investigated designs. Results are shown as mean values with the corresponding standard deviations. For the linear regressions, the coefficient of determination is shown.

In Figure 8, the influence of the geometrical parameters width $(a)$ and strut diameter $(d)$ on the elastic modulus was taken into account and revealed a correlation similar to that of the effect of porosity on the elastic modulus. All three designs showed that a decreasing $a / d$ ratio leads to a higher elastic modulus. The cubic and pyramidal designs show a lower elastic modulus than the twisted design at the same $a / d$ ratio. While the cubic and pyramidal designs at ratios from 2.5 to 2.7 have an elastic modulus between 6.91 and 9.25, the elastic modulus of the twisted design is 21.38. 


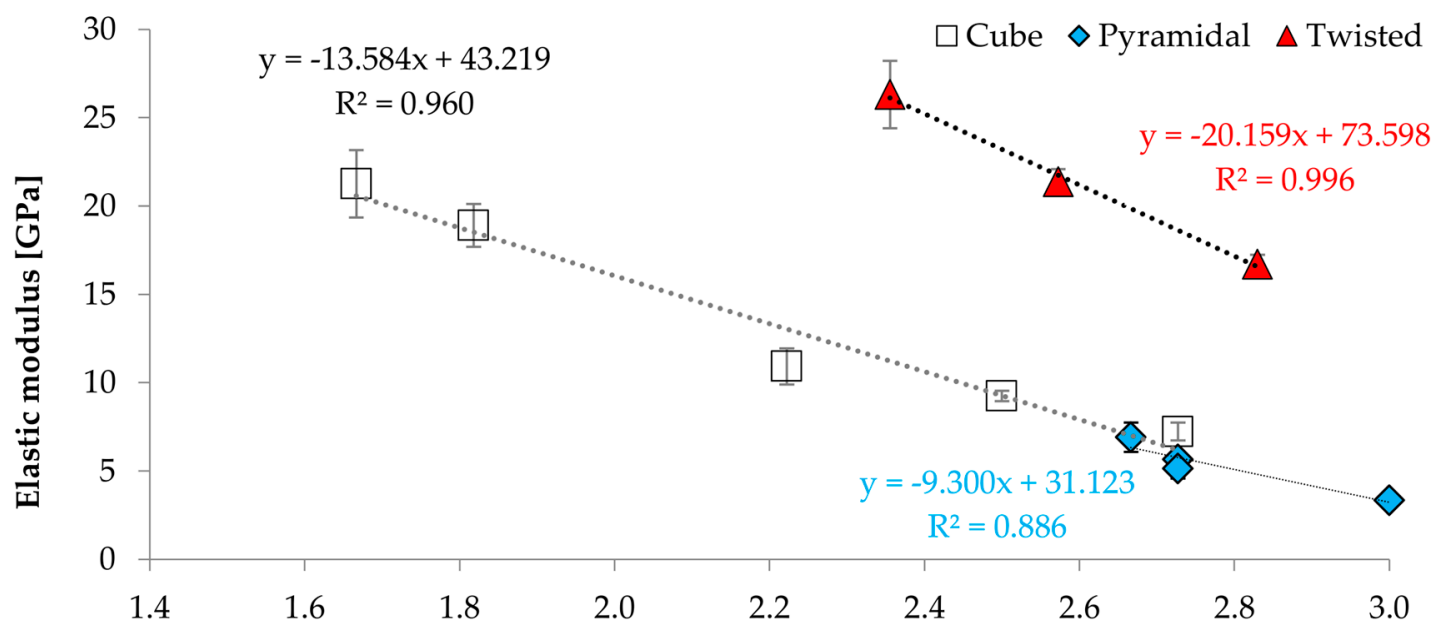

Ratio between width (a) per strut diameter (d)

Figure 8. Correlation between the ratio $a / d$ (width (a) and strut diameter $(d)$ ) and elastic modulus in each of the investigated designs. Results are shown as mean values with the corresponding standard deviations. For the linear regressions, the coefficient of determination is shown.

The correlation between compressive strength and the elastic modulus also revealed linear dependencies with high coefficients of determination of over $90 \%$ as shown in Figure 9.

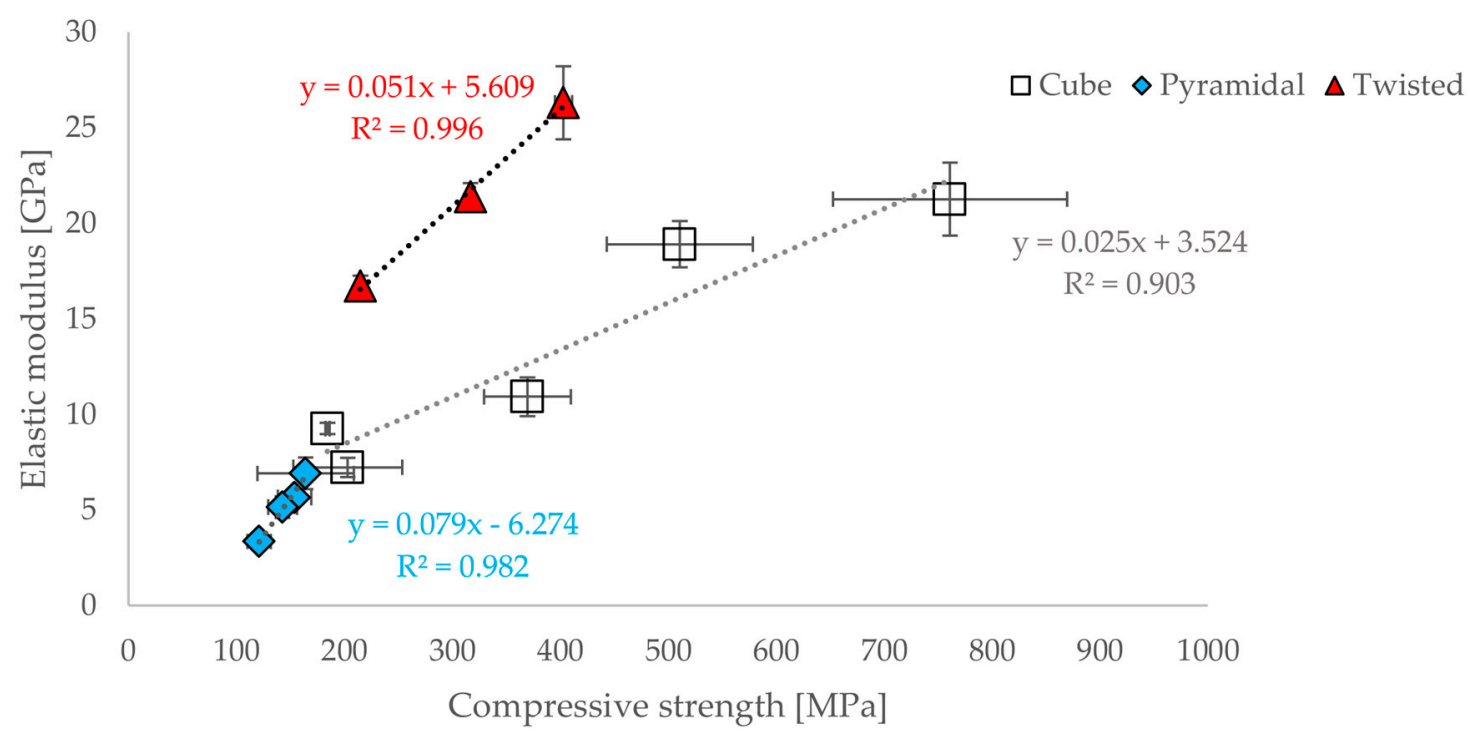

Figure 9. Correlation between compressive strength and elastic modulus in each of the investigated designs. Results are shown as mean values with the corresponding standard deviations. For the linear regressions, the coefficient of determination is shown.

The elastic modulus increased with increasing compressive strength for all three designs. The slopes for the cube, twisted and pyramidal designs varied between 0.025, 0.051 and 0.079 , respectively. Depending on the design, such an increase can lead to considerable changes. The smaller the increase, the lower is the possible change in mechanical property. Besides the direct correlation between mechanical properties and the geometrical parameters, there is a correlation between the elastic modulus and the scaffold porosity and the elastic modulus ratio [53]. This correlation was investigated for the three tested designs (Figure 10). 


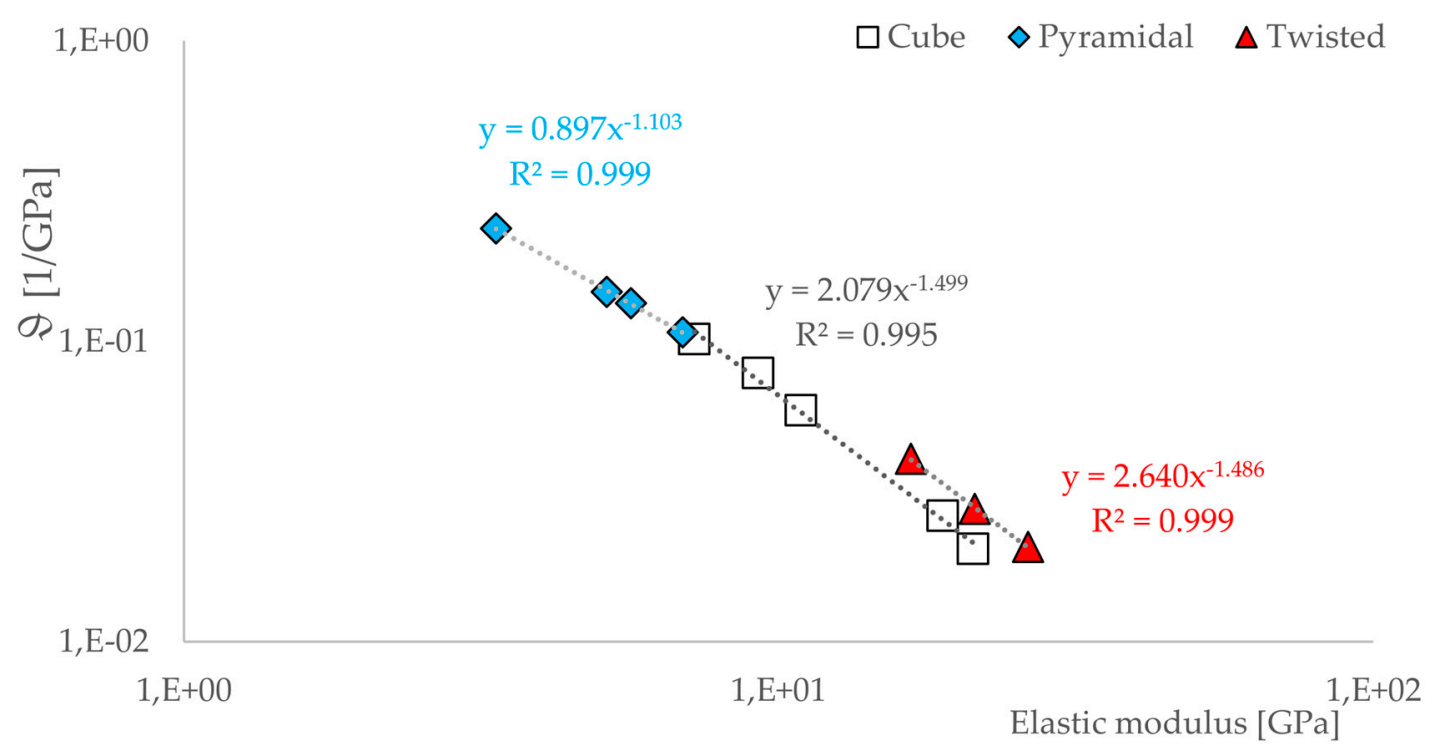

Figure 10. Relationship between elastic modulus for a design and the ratio between porosity and modulus $\vartheta$ correlation.

According to our results, the porosity and elastic modulus ratio can be described as:

$$
\vartheta=\frac{\text { porosity [absolute] }}{\text { elastic moduls [GPa] }}
$$

For the investigated designs, we used the power law

$$
\vartheta=k \times E^{\alpha}
$$

where $k$ is a consistency factor and $\alpha$ is an exponent describing the structural behaviour. $E$ is the elastic modulus [GPa] of the structural part.

For the twisted design made of Ti6Al4V, factor $k$ is 2.640 and exponent $\alpha$ is -1.486 . For the cube design made of Ti6Al4V, factor $k$ is 2.079 and exponent $\alpha$ is -1.499 . Factor $k$ for the pyramidal design is 0.897 and $\alpha$ is -1.103 . The three design types showed high correlations at $99.9 \%, 99.5 \%$ and $99.9 \%$ with this power law.

All three design types show the same functional characteristics. Factor $\alpha$ is negative and describes the clipping of the elastic modulus with a decreasing ratio between porosity and elastic modulus.

To verify the power law (5), we compared results from the literature [32,54] for different structures manufactured by means of SLM using TI6AL4V (Figure 11). These results show that the power law is valid. Results obtained by Wieding et al. $\left(R^{2}=1\right)$ and Yavari et al. $\left(R^{2}=0.9998\right)$ have a high correlation. The power law is also valid if the orientation of a unit cell varies at constant scaffold orientation within the building space. These results are shown by Weißmann et al. [53] for the twisted design in different unit cell orientations with a correlation of $100 \%$. 


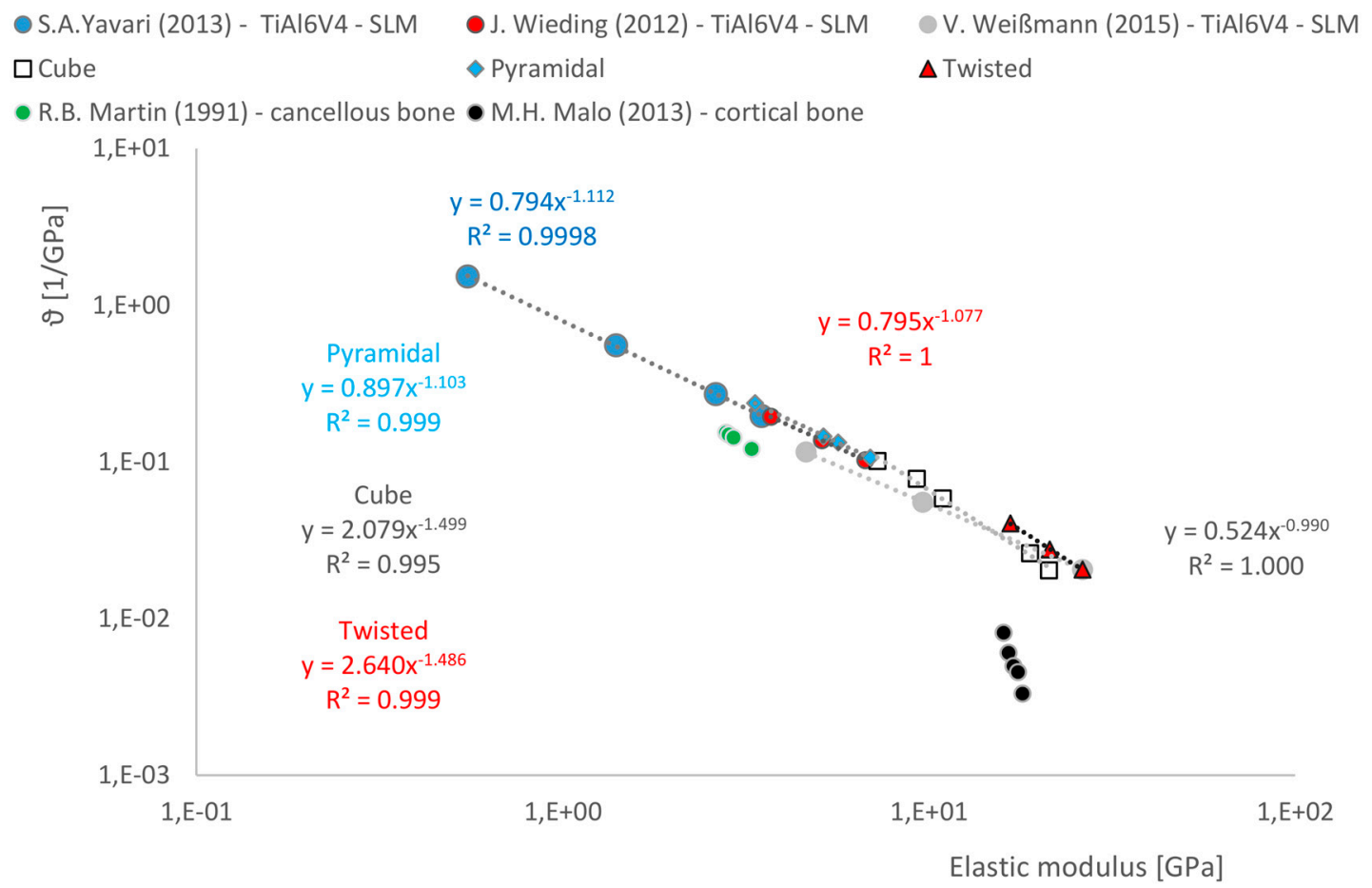

Figure 11. Relationship between E-modulus and the E-modulus-porosity correlation in comparison with examples from literature with regard to Ti6Al4V and in comparison with cancellous and cortical bone.

\section{Discussion}

By using additive manufacturing methods, open-porous scaffolds can be fabricated in a wide range of design variations with specific properties that fulfil both mechanical and biological requirements $[10,27,32,55]$.

In this study, the influence of the structural design was investigated. The generated designs varied with respect to geometry, dimension and porosity. The latter exhibited values between $43 \%$ and $80 \%$ that correspond to porosities found in the literature that are interesting for the application of porous structures $[25,26,56,57]$. Accuracy of the fabricated scaffolds is mandatory for the evaluation of the mechanical properties of open-porous structures. The porosities for scaffolds made by us were calculated and revealed high accordance with the porosities derived from CAD data with deviations less than $3.2 \%$.

Apart from the build parameters (Table 3), it is also the orientation of individual struts within the structures (scaffold) that has an influence on porosity. Build parameters such as laser power, scan speed and hatch distance [58-60], which influence surface morphology, macro- and micro-porosity, can be predominantly excluded here due to the identical parameters used.

Table 3. Overview of energy-relevant process parameters which were used in the building of all models.

\begin{tabular}{cccc}
\hline Parameter & Description & Unit & Process Parameter \\
\hline$P$ & Laser Power & $\mathrm{W}$ & 275 \\
$v$ & Scan speed & $\mathrm{mm} / \mathrm{s}$ & 805 \\
$d$ & Hatch spacing & $\mu \mathrm{m}$ & 120 \\
$t$ & Layer thickness & $\mu \mathrm{m}$ & 30 \\
\hline
\end{tabular}


All scaffold designs were manufactured in the same building direction. Because it is known that subsequent post-processing (sand-blasting, ultrasonic cleaning, chemical etching, etc.) has an influence on the surface and therefore on porosity, post-treatment steps were avoided.

What is much more interesting here is the orientation of struts during the building process. As Suard et al. [61] described, the surface roughness and the resulting strut shape depend on the orientation during the building process. Whereas vertically oriented struts display uniform roughness values, a horizontal or oblique orientation leads to an increased roughness of struts which is mainly attributable to energy flows into the powder bed. Due to this energy flow, powder particles repeatedly tend to adhere to the strut underside (Figure 4). This phenomenon causes deviations from the present geometry as well as porosity deviations. The effect of powder adhesion is also described in [62].

The structures made in the course of this study exhibit vertical and horizontal struts in the models C1-C5. The pyramid-shaped structural elements display, apart from horizontal struts, struts with an oblique orientation, while torsional structures are exclusively built up with obliquely oriented struts. The lower porosity of pyramidal structures determined by way of experiment is attributable to the orientation of the struts. The scaffolds consisting of cubes show lower experimentally determined porosities, especially when it comes to struts with larger cross-sections (C1-2.2 mm, C2-1.8 mm). Apparently, the diameter and thereby, indirectly, the required energy input too, play a role in the cube structures with horizontal and vertical struts. Since the torsional structure is also inconsistent (T1, T3-lower porosity; T2-higher porosity), there seems to be an influence here.

These facts offer the possibility for scaffold fabrication with mechanical properties that can be predetermined by CAD design analysis or by numerical simulations [63] before manufacturing. All samples showed a failure behaviour, which is known from the literature. A shear deformation at an angle of ca. $45^{\circ}$ is shown in Figure 5 for the twisted and pyramidal design. The cubic design showed a layer-by-layer failure mechanism. This is in accordance with the results of Cheng et al. [64], Xiao et al. [65] and Li et al. [23]. Using computationally predicted deformation models, Kadkhodapour et al. [66] show that a layer-by-layer failure mechanism applies to stretch-dominated structures (i.e., cubic unit cell) while bending-dominated structures (i.e., twisted, pyramidal) show shear bands at $45^{\circ}$. Due to the geometrical variation of the structural design, the elastic modulus could be varied between $7 \mathrm{GPa}$ and approximately $22 \mathrm{GPa}$ for the cubic design, between $3 \mathrm{GPa}$ and approximately $7 \mathrm{GPa}$ for the pyramidal design and between $17 \mathrm{GPa}$ and $26 \mathrm{GPa}$ for the twisted design. Thus, we could demonstrate the possibility of generating scaffolds with specific mechanical properties within the reported range for human cortical bone [4,28]. Moreover, modification and reduction of scaffold stiffness is necessary to prevent stress shielding of the adjacent bone tissue around stiff implants $[7,8]$.

Based on uniaxial compression testing for the three investigated design variations, linear correlation with a high coefficient of determination of the elastic modulus with scaffold porosity (Figure 7) and compressive strength (Figure 9) were found. The correlations between elastic modulus and porosity and between elastic modulus and geometrical parameters were very similar.

The influence of the length of the individual load-bearing bars on the achievable mechanical properties is directly connected to the load-bearing section. As shown in Figure 8, this correlation can be described as the ratio of the width of unit structure $(a)$ and strut diameter $(d)$. The existing pyramid and cubic unit cell structures, which are geometrically similar, here describe a different stiffness level than the structures of the twisted unit cells. Similarly, there is a bigger quotient of unit cells with higher porosities. The ascertained functional linear connection thus offers another possibility to influence the mechanical qualities by providing specific geometrical constraints.

Cell size has a significant influence on the mechanical behaviour of open-porous structures or cellular materials $[50,51,65]$. A characterization of the effect of cell size on the mechanical properties is possible using the length ratio $\lambda$. $\lambda$ is defined as $\lambda=L / L_{S}$, where $L$ is the cell size and $L_{S}$ is the size of the specimen. Results of this study show that the design with the smaller $\lambda$ achieves higher results in the elastic modulus. This relationship does not apply universally and to all tested design types. However, in general, this knowledge can be confirmed. Accordingly, the results for the cubic design 
range from 0.188 to 0.133 and from 0.32 to 0.3 for the pyramidal design. The E moduli for the cubic design are between 7.2 and $21.6 \mathrm{MPa}$, and those for the pyramidal design are between 3.4 and $6.9 \mathrm{MPa}$.

This shows that a lower value corresponds to $\lambda$ with higher values for the $\mathrm{E}$ modulus. A comparison of the pyramidal design with the twisted design $(\lambda=0.166-0.222$ and elastic modulus 16.7-26.2 MPa) confirmed this relationship. When comparing the cubic and the twisted design, this connection is not generally valid. Differences found with regard to the E modulus can be explained by the buckling length of individual struts and the position of the strut to the acting force. Thus, when comparing T2 with C2, the elastic modulus of the twisted design types is higher than that of the cubic design in spite of the reduced cross section. The structure has rigidity advantages over the cubic structure. The bars of the cubic design are aligned directly perpendicular to the acting force (larger free buckling length), and there is no mutual support as in the twisted design.

These partially valid relationships that are difficult to overlook in their complexity require a simple way of characterization. Core aspects for describing porous structures include, of course, the porosity and the obtained mechanical properties-specifically of the elastic modulus. With the application of such structural elements in medical fields or in particular in implants, where porous structures are intended to fulfil bone-like functions, rigidity in the context of porosity plays an essential role. Characterization of the specific yielding of structures as a measure of the stiffness of porosity offers an immediate option to assess the suitability of structure types and their geometric variations for their envisaged field of application. As shown in Figures 10 and 11, the individual design types differ clearly with respect to their mechanical properties.

To determine the mechanical properties, a uniaxial compression test was conducted. Based on these tests, a correlation between the elastic modulus and the scaffold porosity and elastic modulus ratio could be verified and described in the power law (5). This power law (5) could be verified for different structures (Figure 11) manufactured with SLM using TI6AL4V [10,64]. Specific yielding indicates how well a structure (geometrical variation) fulfils the requirements in terms of stiffness and porosity. It describes the resistance that is put up by the structure against deformation caused by the acting force. The active cross-sectional area, the material and the influencing manufacturing factors have a direct impact on the characterization of specific yielding. Density is typically taken into account in order to describe specific technology parameters. In the power law (4), the porosity of the structure, or in other words, a macro density is used for evaluation.

Factor $\vartheta$ describes this relationship very well, thus combining the requirements placed on components for medical applications, i.e., the description of a sufficiently high porosity, to ensure the secondary stiffness required for the successful retention of the implant and on mechanical stiffness necessary for the absorption of the acting loads to avoid stress shielding.

The investigated structures compared with values from the literature as well as our own investigations are shown in (Figure 11). These results are used in reference to the characteristic values for human bones. An evaluation and comparison with the listed structures is possible by looking at the porosity of cortical bone (between 6\%-13\%) [67] and cancellous bone (between 38\%-43\%) [68] in relation to known literature values for the elastic modulus (cancellous bone-2.5-3.5 GPa; cortical bone-15-18 GPa).

Figure 11 impressively underlines that human bone is superior with regard to specific yielding for each generated elastic modulus. It also shows that there is a need to develop structures with properties that can compete with the characteristics of the human bone. Specific yielding as the determining factor for characterizing the resistance against deformation offers an invaluable benefit in the assessment of the suitability of a given structure for medical applications (implant). Since specific yielding is directly related to the volume of structures, it is possible to selectively decide which geometries, i.e., which structures, are to be preferred. The simple and comparative description of mechanical properties in the context of porosity offers another important means to assign structures to specific areas of application (cortical or trabecular bone areas) and functions (hips, knees). In a further step, it would be interesting to determine how the detected regularities manifest themselves under dynamic load. 


\section{Conclusions}

The mechanical behaviour of Ti6AL4V lattice structures fabricated via an SLM was examined experimentally by choosing different unit cell geometries. Three groups with different cell sizes were adopted in the test.

The following specific conclusions have been reached:

- In our work, we could demonstrate the possibility of fabricating different scaffold structures made of Ti6Al4V with high geometrical accuracy by using the SLM process. Porosity of the fabricated scaffolds differed less than $3.2 \%$ from the idealized porosity of the scaffolds as calculated by CAD.

- Based on tests under uniaxial loading conditions, the influence of unit cell dimension and of porosity on the mechanical properties was demonstrated.

- The size variation in unit cell dimension results in a change of their mechanical properties, this can be attributed to

the geometric conditions of the unit cell, in particular the length ratio;

the position of the struts towards the affected force

- A functional correlation between elastic modulus and compressive strain or compressive strength for all three geometric designs could be established.

- Nevertheless, a functional correlation with regard to the ratio of width of unit structure $(a)$ and strut diameter $(d)$ could be established.

- There is a relationship between the porosity and the elastic modulus of open-porous structures. This relationship is valid for all tested structures and describable with the power law (5). The relationship is consistent with that found in other open-cell structures fabricated from Ti6AL4V by SLM. A direct comparison with human bone is possible. Since specific yielding is directly related to the volume of structures, it is possible to selectively decide which geometries, i.e., which structures are to be preferred.

- All scaffolds were strong enough to bear the impacting loads and achieved an elastic modulus within the specified range of human cortical bone depending on the geometrical parameter variations.

In our work, we could demonstrate the possibility of fabricating different scaffold structures made of Ti6Al4V with high geometrical accuracy by using the SLM process. Porosity of the fabricated scaffolds differed by less than $3.2 \%$ from the idealized porosity of the scaffolds calculated by CAD. All scaffolds were able to carry the loading and revealed an elastic modulus within the specified range of human cortical bone depending on the geometrical parameter variations.

Acknowledgments: We are grateful for the financial support provided by the Ministry for Economy, Construction and Tourism of Mecklenburg-Vorpommern (V-630-F-122-2011) and the Federal Ministry of Education and Research (03FH005IX5).

Author Contributions: We point out that all authors were fully involved in the study and in preparing the manuscript. V.W., A.W., and J.W. designed the study. V.W. generated the CAD models with the support of H.H. and was involved in the manufacturing process of the scaffolds. V.W., and J.W. performed the experiments, analysed the data with support of N.L., and A.W. and wrote the initial manuscript. H.H., and R.B. organized the research funding. All authors ensured the accuracy of the data and the analyses and reviewed the manuscript in its current state.

Conflicts of Interest: The authors declare no conflicts of interest.

\section{References}

1. Vannoort, R. Titanium-The Implant Material of Today. J. Mater. Sci. 1987, 22, 3801-3811. [CrossRef]

2. Wirtz, D.C.; Bader, C.; Reichel, H. Revisionsendoprothetik der Hüftpfanne; Springer Medizin Verlag: Heidelberg, Germany, 2008. 
3. Long, M.; Rack, H.J. Titanium alloys in total joint replacement-A material science perspective. Biomaterials 1998, 19, 1621-1639. [CrossRef]

4. Öhmann, C.; Baleani, M.; Pani, C.; Taddei, F.; Alberghini, M.; Viceconti, M.; Manfrini, M. Compressive behaviour of child and adult cortical bone. Bone 2011, 49, 2011. [CrossRef] [PubMed]

5. Bahraminasab, M.; Sahari, B.B.; Edwards, K.L.; Frahmand, F.; Arumugam, M. Aseptic loosening of femoral components-Materials engineering and design considerations. Mater. Des. 2013, 44, 155-163. [CrossRef]

6. Tigges, S.; Stiles, R.G.; Roberson, J.R. Complications of Hip-Arthroplasty Causing Periprosthetic Radiolucency on Plain Radiographs. Am. J. Roentgenol. 1994, 162, 1387-1391. [CrossRef] [PubMed]

7. Merle, C.; Streit, M.R.; Volz, C.; Pritsch, M.; Gotterbarm, T.; Aldinger, P.R. Bone remodeling around stable uncemented titanium stems during the second decade after total hip arthroplasty: A DXA study at 12 and 17 years. Osteoporos. Int. 2011, 22, 2879-2886. [CrossRef] [PubMed]

8. Niinomi, M.; Nakai, M. Titanium-Based Biomaterials for Preventing Stress Shielding between Implant Devices and Bone. Int. J. Biomater. 2011. [CrossRef] [PubMed]

9. Harrysson, O.L.; Cansizoglu, O.; Marcellin-Little, D.J.; Cormier, D.R.; West, H.A. Direct metal fabrication of titanium implants with tailored materials and mechanical properties using electron beam melting technology. Mater. Sci. Eng. C Biomim. Supramol. Syst. 2008, 28, 366-373. [CrossRef]

10. Murr, L.E.; Gaytan, S.M.; Medina, F.; Lopez, H.; Martinez, E.; Machado, B.I.; Hernandez, D.H.; Martinez, L.; Lopez, M.I.; Wicker, R.B.; et al. Next-generation biomedical implants using additive manufacturing of complex, cellular and functional mesh arrays. Philos. Trans. R. Soc. A 2010, 368, 1999-2032. [CrossRef] [PubMed]

11. Khanoki, S.A.; Pasini, D. Fatigue design of a mechanically biocompatible lattice for a proof-of-concept femoral stem. J. Mech. Behave. Biomed. Mater. 2013, 22, 65-83. [CrossRef] [PubMed]

12. Bougherara, H.; Bureau, M.N.; Ya, L. Bone remodeling in a new biomimetic polymer-composite hip stem. J. Biomed. Mater. Res. Part A 2009, 92, 164-174. [CrossRef] [PubMed]

13. Huiskes, R.; Weinans, H.; van Rietbergen, B. The relationship between stress shielding and bone resoprtion around hip stem and the effects of flexible materials. Clin. Orthop. Relat. Res. 1992, 274, 124-134. [PubMed]

14. Yan, W.; Berthe, J.; Wenc, C. Numerical investigation of the effect of porous titanium femoral prosthesis on bone remodelling. Mater. Des. 2011, 32, 1776-1782. [CrossRef]

15. Imwinkelried, T. Mechanical properties of open-porous titanium foam. J. Biomed. Mater. Res. A 2007, 81, 964-970. [CrossRef] [PubMed]

16. Li, J.P.; Wijn, J.R.; van Blitterswijk, C.A.; de Groot, K. Comparison of porous Ti6Al4V made by sponge replication and directly 3D fiber deposition and cancellous bone. Key Eng. Mater. 2007, 330-332, 999-1002. [CrossRef]

17. Mueller, U.; Imwinkelried, T.; Horst, M.; Sievers, M.; Graf-Hausner, U. Do human osteoblasts grow into open-porous titanium? Eur. Cell Mater. 2006, 11, 8-15.

18. Cachinho, S.C.; Correia, R.N. Titanium scaffolds for osteointegration: Mechanical, in vitro and corrosion behaviour. J. Mater. Sci. Mater. Med. 2008, 19, 451-457. [CrossRef] [PubMed]

19. Challis, V.J.; Roberts, A.P.; Grotowski, J.F.; Zhang, L.C.; Sercombe, T.B. Prototypes for Bone Implant Scaffold Designed via Topolgy Optimation and Manufactured by Solid Freeform Fabrication. Adv. Eng. Mater. 2010, 12, 1106-1110. [CrossRef]

20. Cheah, C.M.; Chua, C.K.; Leong, K.F.; Cheong, C.H.; Naing, M.W. Automatic algorithm for generating complex polyhedral scaffold strutures for tissue engineering. Tissue Eng. 2004, 10, 595-610. [CrossRef] [PubMed]

21. Emmelmann, C.; Scheinemann, P.; Munsch, M.; Seyda, V. Laser additive manufacturing of modified implant surfaces with osseointegrate characteristics. Phys. Procedia 2011, 12, 375-384. [CrossRef]

22. Hazlehurst, K.; Wang, C.J.; Stanford, M. Evaluation of the stiffness characteristics of square pore CoCrMo cellular structures manufactured using laser melting technology for potential orthopaedic applications. Mater. Des. 2013, 51, 949-955. [CrossRef]

23. Li, S.J.; Xu, Q.S.; Wang, Z.; Hou, W.T.; Hao, Y.L.; Yang, R.; Murr, L.E. Influence of cell shape on mechanical properties of Ti-6Al-4V meshes fabricated by electron beam melting method. Acta Biomater. 2014, 10, 4537-4547. [CrossRef] [PubMed]

24. Luxner, M.H.; Stampfl, J.; Pettermann, H.E. Finite element modeling concepts and linear analyses of 3D regular open cell structures. J. Mater. Sci. 2005, 40, 5859-5866. [CrossRef] 
25. Parthasarathy, J.; Starly, B.; Raman, S.; Christensen, A. Mechanical evaluation of porous titanium (Ti6Al4V) structures with electron beam melting (EBM). J. Mech. Behav. Biomed. Mater. 2010, 3, 249-259. [CrossRef] [PubMed]

26. Ryan, G.E.; McGarry, P.; Pandit, A.; Apatsidis, D. Analysis of the Mechanical Behavior of a Titanium Scaffold with a repeating unit-cell substructure. J. Biomed. Mater. Res. B Appl. Biomater. 2009, 90, 894-906. [CrossRef] [PubMed]

27. Schwerdtfeger, J.; Heinl, P.; Singer, R.F.; Koerner, C. Auxetic cellular structures through selective electron-beam melting. Phys. Status Solid B Basic Solid State Phys. 2010, 247, 269-272. [CrossRef]

28. Grimal, Q. Assessment of cortical bone elasticity and strength: Mechanical testing and ultrasound provide complementary data. Med. Eng. Phys. 2009, 31, 1140-1147. [CrossRef] [PubMed]

29. Lewis, G. Properties of open-cell porous metals and alloys for orthopaedic applications. J. Mater. Sci. Mater. Med. 2013, 24, 2293-2325. [CrossRef] [PubMed]

30. Jonitz-Heincke, A.; Wieding, J.; Schulze, C.; Hansmann, D.; Bader, R. Comparative analysis of the oxygen supply and viability of human osteoblasts in three-dimensional titanium scaffolds produced by laser-beam or electron beam melting. Materials 2013, 6, 5398-5409. [CrossRef]

31. Wieding, J.; Wolf, A.; Bader, R. Numerical optimization of open-porous bone scaffold structures to match the elastic properties of human cortical bone. J. Mech. Behav. Biomed. Mater. 2014, 37, 56-68. [CrossRef] [PubMed]

32. Wieding, J.; Jonitz, A.; Bader, R. The Effect of Structural Design on Mechanical Properties and Cellular Response of Additive Manufactured Titanium Scaffolds. Materials 2012, 5, 1336-1347. [CrossRef]

33. Geetha, M.; Singh, A.K.; Asokamani, R.; Gogia, A.K. Ti based biomaterials, the ultimate choice for orthopaedic implants-A review. Prog. Mater. Sci. 2009, 54, 397-425. [CrossRef]

34. Wauthle, R.; van der Stok, J.; Yavari, S.A.; van Humbeeck, J.; Kruth, J.P.; Zadpoor, A.A.; Weinans, H.; Mulier, M.; Schrooten, J. Additively manufactured porous tantalum implants. Acta Biomater. 2015, 14, 217-225. [CrossRef] [PubMed]

35. Attar, H.; Löber, L.; Funk, A.; Calin, M.; Zhang, L.C.; Prashanth, K.G. Mechanical behavior of porous commercially pure Ti and Ti-TiB composite materials manufactured by selective laser melting. Mater. Sci. Eng. A 2015, 625, 350-356. [CrossRef]

36. Wauthle, R.; Ahmadi, S.M.; Yavari, S.A.; Mulier, M.; Zadpoor, A.A.; Weinans, H.; van Humbeeck, J.; Kruth, J.P.; Schrooten, J. Revival of pure titanium for dynamically loaded porous implants using additive manufacturing. Mater. Sci. Eng. C 2015, 54, 94-100. [CrossRef] [PubMed]

37. Rivera, S.; Panera, M.; Miranda, D.; Varela, F. Development of dense and cellular solids in CrCoMo alloy for orthopaedic applications. Procedia Eng. 2011, 10, 2979-2987. [CrossRef]

38. Yavari, S.A.; Ahmadi, S.M.; Wauthle, R.; Pouran, B.; Schrooten, J.; Weinans, H.; Zadpoor, A.A. Relationship between unit cell type and porosity and the fatigue behavior of selective laser melted meta-biomaterials. J. Mech. Behav. Biomed. Mater. 2015, 43, 91-100. [CrossRef] [PubMed]

39. Challis, V.J.; Xu, X.; Zhang, L.C.; Roberts, A.P.; Grotowski, J.F.; Sercombe, T.B. High specific strength and stiffness structures produced using selective laser melting. Mater. Des. 2014, 63, 783-788. [CrossRef]

40. Marin, E.; Fusi, S.; Pressacco, M.; Paussa, L.; Fedrizzi, L. Characterization of cellular solids in Ti6Al4V for orthopaedic implant applications: Trabecular titanium. J. Mech. Behav. Biomed. Mater. 2010, 3, 373-381. [CrossRef] [PubMed]

41. Markhoff, J.; Wieding, J.; Weißmann, V.; Pasold, J.; Jonitz-Heincke, A.; Bader, R. Influence of Different Three-Dimensional Open Porous Titanium Scaffold Designs on Human Osteoblasts Behavior in Static and Dynamic Cell Investigations. Materials 2015, 8, 5490-5507. [CrossRef]

42. Song, B.; Dong, S.; Zhang, B.; Liao, H.; Coddet, C. Effects of processing parameters on microstructure and mechanical property. Mater. Des. 2012, 35, 120-125. [CrossRef]

43. Attar, H.; Calin, M.; Zhang, L.C.; Scudino, S.; Eckert, J. Manufacture by selective laser melting and mechanical behavior of commercially pure titanium. Mater. Sci. Eng. A 2014, 593, 170-177. [CrossRef]

44. Yadroitsev, I.; Krakhmalev, P.; Yadroitsava, I. Selective laser melting of Ti6Al4V alloy for biomedical applications temperature monitoring and microstructural evolution. J. Alloy. Compd. 2014, 583, 404-409. [CrossRef]

45. Vrancken, B.; Thijs, L.; Kruth, J.P.; van Humbeeck, J. Heat treatment of Ti6Al4V produced by Selective Laser Melting: Microstructure and mechanical properties. J. Alloy. Compd. 2012, 541, 177-185. [CrossRef] 
46. Gibson, L.J.; Ashby, M.F.; Schajer, G.S.; Robertson, C.I. Mechanics of two-dimensional cellular materials. Proc. R. Soc. Lond. Ser. A Math. Phys. Sci. 1982. [CrossRef]

47. Sanz-Herrera, J.A.; Doblare, M.; Garcia-Aznar, J.M. Scaffold microarchitecture determines internal bone directional growth structure: A numerical study. J. Biomech. 2010, 43, 2480-2486. [CrossRef] [PubMed]

48. Campoli, G.; Borleffs, M.S.; Yavari, S.A.; Wauthle, R.; Weinans, H.; Zadpoor, A.A. Mechanical properties of open-cell metallic biomaterials manufactured using additive manufacturing. Mater. Des. 2013, 49, 957-965. [CrossRef]

49. Heinl, P.; Müller, L.; Körner, C.; Singer, R.F.; Müller, F.A. Cellular Ti-6Al-4V structures with interconnected macro porosity. Acta Biomater. 2008, 4, 1536-1544. [CrossRef] [PubMed]

50. Onck, P.R.; Andrews, E.W.; Gibson, L.J. Size effects in ductile cellular solids. Part I: Modeling. Int. J. Mech. Sci. 2001, 43, 681-699. [CrossRef]

51. Andrews, E.W.; Gioux, G.; Onck, P.; Gibson, L.J. Size effects in ductile cellular solids. Part II: Experimental results. Int. J. Mech. Sci. 2001, 43, 701-713. [CrossRef]

52. Bartolomeu, F.; Faria, S.; Carvalho, O.; Pinto, E.; Alves, N.; Silva, F.S.; Miranda, G. Predictive models for physical and mechanical properties of Ti6Al4V produced by selective laser melting. Mater. Sci. Eng. A 2016, 663, 181-192. [CrossRef]

53. Weißmann, V.; Bader, R.; Hansmann, H.; Laufer, N. Influence of the structural orientation on the mechanical properties of selective laser melted Ti6Al4V open-porous scaffolds. Mater. Des. 2016, 95, 188-197. [CrossRef]

54. Yavari, S.A.; Wauthle, R.; van der Stok, J.; Riemslag, A.C.; Janssen, A.C.; Mulier, M.; Kruth, J.P.; Schrooten, J.; Weinans, H.; Zadpoor, A.A. Fatigue behavior of porous biomaterials manufactured using selective laser melting. Mater. Sci. Eng. C 2013, 33, 4849-4858. [CrossRef] [PubMed]

55. Jonitz-Heincke, A.; Wieding, J.; Schulze, C.; Hansmann, D.; Bader, R. Comparative Analysis of the Oxygen Supply and Viability of Human Osteoblasts in Three-Dimensional Titanium Scaffolds Produced by Laser-Beam or Electron-Beam Melting. Materials 2013, 6, 5398-5409. [CrossRef]

56. Olivares, A.L.; Marsal, E.; Planell, J.A.; Lacroix, D. Finite element study of scaffold architecture design and culture conditions for tissue engineering. Biomaterials 2009, 30, 6142-6149. [CrossRef] [PubMed]

57. Li, X.; Wang, C.T.; Zhang, W.G.; Li, Y.C. Fabrication and compressive properties of Ti6Al4V implant with honeycomb-like structure for biomedical applicatios. Rapid Prototyp. J. 2010, 16, 44-49. [CrossRef]

58. Abele, E.; Stoffregen, H.A.; Kniepkamp, M.; Lang, S. Selective laser melting for manufacturing of thin-walled porous elements. J. Mater. Process. Technol. 2015, 215, 114-122. [CrossRef]

59. Yadroitsev, I.; Smurov, I. Surface Morphology in Selective Laser Melting of Metal Powders. Phys. Procedia 2011, 12, 264-270. [CrossRef]

60. Kasperovich, G.; Hausmann, J. Improvement of fatigue resistance and ductility of TiAl6V4 processed by selective laser melting. J. Mater. Process. Technol. 2015, 220, 202-214. [CrossRef]

61. Suard, M.; Martin, G.; Lhuissier, P.; Dendievel, R.; Vignat, F.; Blandin, J.-J. Mechanical equivalent diameter of single struts for the stiffness prediction of lattice structures produced by electron beam melting. Addit. Manuf. 2015, 8, 124-131. [CrossRef]

62. Zhang, S.; Wei, Q.; Cheng, L.; Li, S.; Shi, Y. Effects of scan line spacing on pore characteristics and mechanical properties of porous Ti6Al4V implants fabricated by selective laser melting. Mater. Des. 2014, 63, 185-193. [CrossRef]

63. Wieding, J.; Souffrant, R.; Mittelmeier, W.; Bader, R. Finite element analysis on the biomechanical stability of open-porous titanium scaffolds for large segmental bone defects under physiological load conditions. Med. Eng. Phys. 2013, 35, 422-432. [CrossRef] [PubMed]

64. Cheng, X.Y.; Li, S.J.; Murr, L.E.; Zhang, Z.B.; Hao, Y.L.; Yang, R.; Medina, F.; Wicker, R.B. Compression deformation behavior of Ti-6Al-4V alloy with cellular structures fabricated by electron beam melting. J. Mech. Behav. Biomed. Mater. 2012, 16, 153-162. [CrossRef] [PubMed]

65. Xiao, L.; Song, W.; Wang, C.; Liu, H.; Tang, H.; Wang, J. Mechanical behavior of open-cell rhombic dodecahedron Ti-6Al-4V lattice structure. Mater. Sci. Eng. A 2015, 640, 375-384. [CrossRef]

66. Kadkhodapour, J.; Montazerian, A.C.; Darabi, A.P.; Anaraki, A.P.; Ahmadi, S.M.; Zadpoor, A.A.; Schmauder, S. Failure mechanisms of additively manufactured porous biomaterials: Effects of porosity and type of unit cell. J. Mech. Behav. Biomed. Mater. 2015, 50, 180-191. [CrossRef] [PubMed] 
67. Malo, M.H.; Rohrbach, D.; Isaksson, H.; Töyräs, J.; Jurvelin, J.S.; Tamminen, I.S. Longitudinal elastic properties and porosity of cortical bone tissue vary with age in human proximal femur. Bone 2013, 53, 451-458. [CrossRef] [PubMed]

68. Martin, R.B. Determinants of the mechanical properties of bones. J. Biomech. 1991, 24, 79-88. [CrossRef]

(c) 2016 by the authors; licensee MDPI, Basel, Switzerland. This article is an open access article distributed under the terms and conditions of the Creative Commons Attribution (CC-BY) license (http://creativecommons.org/licenses/by/4.0/). 